\title{
Performance evaluation of Holstein Frisian cattle under subtropical environment
}

\author{
Rameez Raja Kaleri ${ }^{1 *}$, Hubdar Ali Kaleri ${ }^{1}$, Shahla Karim Baloch ${ }^{2}$, Asma \\ Kaleri ${ }^{1}$, Gulam Murtaza Mari ${ }^{1}$, Abdullah Mari ${ }^{1}$, Mujahid Ali Shah ${ }^{1}$, \\ Mehran Ali Chalgri ${ }^{2}$, Ikram Ul Hak Kakar ${ }^{1}$ and Mansoor Ahmed \\ Gopang ${ }^{1}$
}

1. Department of Animal Breeding \& Genetics, Faculty of A. H. \& Vet. Sciences, Sindh Agriculture University, Tandojam-Pakistan

2. Department of Biotechnology, Faculty of Crop Production, Sindh Agriculture University, Tandojam-Pakistan

*Corresponding author's email: rameezkaleri@gmail.com

Rameez Raja Kaleri, Hubdar Ali Kaleri, Shahla Karim Baloch, Asma Kaleri, Gulam Murtaza Mari, Abdullah Mari, Mujahid Ali Shah, Mehran Ali Chalgri, Ikram Ul Hak Kakar and Mansoor Ahmed Gopang. Performance evaluation of Holstein Frisian cattle under subtropical environment. Pure and Applied Biology. Vol. 6, Issue 4, pp1314-1318. http://dx.doi.org/10.19045/bspab.2017.600140

\begin{tabular}{llll}
\hline \hline Received: 03/07/2017 & Revised: 13/10/2017 & Accepted: 14/10/2017 & Online First: 20/10/2017 \\
\hline \hline
\end{tabular}

\section{Abstract}

To evaluate the productive performance of Holstein Friesian cattle maintained at Government Dairy Farm Quetta. For this study the data were collected and utilized for the period of 2006 to 2013. In this study the parameters including effect of sire, parity, effect of season and calving year were under the study. While the heritability and repeatability was analyzed with the method of data analysis. In current study result for milk yield showed that higher milk yield and lactation length were observed in spring season as compared to other seasons. The results of heritability and repeatability for milk yield, lactation length and dry period were low, medium to high. In this study effect of calving season was observed significantly on above traits with low and moderate results of heritability estimate, it is concluded that milk yield, lactation length and dry period are highly influenced by environmental factors.

Keywords: Performance traits; Holstein Frisian; Subtropical environment

\section{Introduction}

Livestock sector of Pakistan serves as back of the national economy, however Pakistan has large number of better dairy animal breed, but due to unawareness regarding the utilization of genetic potential of these animals, now these breeds are known as low milk producer breeds [1]. It is real fact that milk production of these animals can be enhanced either increasing the number of dairy animals or by improving the management practices and changing the environmental conditions [2]. It has been reported that improving the management practices and environmental conditions can play a vital role for producing more effective genetic potential of these dairy breeds [3]. Crossbreeding program is important mating system through this system non descriptive and local breeds of dairy animals can be cross for getting higher genetic potential for fast and better improving method. Due to shortage of higher 
milk producing dairy animal's Pakistani government started to establish various dairy farms of high milk yielding dairy animals such as Jersey and Holstein Frisian in various localities of Pakistan [1]. Heritability is major genetic parameter which represent possible amount of genetic change for different selected traits and repeatability can be defined as inferiority or superiority of any trait that could consider for expression in future [2]. There are number of genetic and environmental factors, which can enhance or reduced the production of these dairy animals, hence this study was designed to evaluate the effect of environment on the performance of Holstein Frisian cows maintained at government dairy form. Quetta.

\section{Material and methods \\ Data source}

Current study was carried out at department of Animal Breeding \& Genetics, Sindh Agriculture University, Tandojam, during the year of 2016. For this purpose data of performance traits including milk yield, lactation length and dry period of Holstein Frisian for the period of 2006 to 2013.

\section{Experimental design \& statistical model}

In this study the data were analyzed with help of (GLM) General linear model procedure, while standard error and arithmetic mean for milk yield lactation length and dry period.

\section{Heritability and repeatability}

The estimation of genetic parameters such as heritability and repeatability were worked out using the formula as suggested by (Becker, 1985).

\section{Results}

\section{Milk yield}

The least square and unadjusted mean was found $338.4 \pm 43.4 \mathrm{~kg}$ and it ranges from 2022 $\mathrm{kg}$ to $6647 \mathrm{~kg}$ with variation of coefficient of 33.81, described in (Table 1). The significant effect of parity was observed significantly higher $(\mathrm{P} \geq 0.05)$. While the effect of season, sire and calving were observed nonsignificant on milk yield, details are presented in (Table 2). In this study the parity number $7^{\text {th }}$ had highest production of milk yield as compared to other parties with 4288 $\mathrm{kg}$. The cows which were calved during the spring season had produced higher production of milk as compared to those cows which were calved during other season. The results of heritability and repeatability estimation for milk yield were observed moderate $0.244 \pm 0.238$ and $0.21 \pm 0.71$; respectively details are mentioned in (Table 1).

\section{Lactation length}

In present study the average lactation length of Holstein Frisian cattle ranged 183 to 511 with mean $356.97 \pm 76.32$ days with variation of coefficient of about $20.93 \%$, details are described in (Tabel-1). The effect of season of calving on lactation length was observed non-significant, details are presented in (Tabel-2). The results of heritability and repeatability estimation for lactation length were observed low $0.19 \pm 0.152$ and $0.189 \pm 0.186$, respectively; details are mentioned in (Table 2).

\section{Dry period}

In this study average dry period was observed $98.12 \pm 51.3$ days and it ranges 3 - to 225 days with variation of coefficient $35.11 \%$, details are described in (Table 1). The effect of season and sire on dry period was found significantly higher $(\mathrm{P} \leq 0.05)$, while the effect of year of calving and parity were observed non-significant on dry period; details are given in (Table 2). The cow that had been calved during the fall season produces lower production of milk as compared to the cows, which have calved in other season. The results of heritability and repeatability estimation were observed moderate $0.61 \pm 0.104$ and $0.189 \pm 0.086$, respectively; details are mentioned in (Table 1). 
Table 1. Performance traits of Holstein Frisian cattle mean standard deviation, range, coefficient of variation, heritability and repeatability

\begin{tabular}{|l|l|l|l|l|l|}
\hline Trait & $\begin{array}{l}\text { Mean Standard } \\
\text { Deviation }\end{array}$ & $\begin{array}{l}\text { Range } \\
(-)(+)\end{array}$ & Cv\% & $\left(\mathrm{h}^{2}\right)$ & $(\mathrm{r})$ \\
\hline Milk Yield & $338.4 \pm 34.4$ & $2022-6447$ & 23.81 & $0.244 \pm 0.238$ & $0.251 \pm 0.07$ \\
\hline $\begin{array}{l}\text { Lactation } \\
\text { length }\end{array}$ & $356.97 \pm 76.32$ & $183-511$ & 20.93 & $0.19 \pm-0.152$ & $0.189 \pm 0.168$ \\
\hline Dry Period & $98.15 \pm 51.3$ & $30-255$ & 35.11 & $0.61 \pm 0.104$ & $0.189 \pm 0.86$ \\
\hline
\end{tabular}

Table 2.The analysis of variance for performance traits of Holstein Frisian cattle

\begin{tabular}{|l|l|l|l|l|l|l|l|l|l|}
\hline & $(\mathrm{DF})$ & $(\mathrm{MS})$ & $(\mathrm{P})$ & $(\mathrm{DF})$ & $(\mathrm{MS})$ & $(\mathrm{P})$ & $(\mathrm{DF})$ & $(\mathrm{MS})$ & $(\mathrm{P})$ \\
\hline Season & 3 & 1131048.45 & 0.109 & 3 & 16702.74 & 0.029 & 3 & 13577.74 & 0.034 \\
\hline Parity & 8 & 1656077.45 & 0.035 & 8 & 3566.24 & 0.610 & 7 & 10550.54 & 0.051 \\
\hline Sire & 6 & 681401.31 & 0.426 & 6 & 4253.96 & 0.482 & 6 & 12471.03 & 0.010 \\
\hline Year & 9 & 263534.62 & 0.854 & 9 & 2028.11 & 0.944 & 8 & 49683.6 & 0.319 \\
\hline Residual & 115 & 776122.77 & - & 115 & 57783.57 & - & 24 & 4955.26 & - \\
\hline Total & 141 & - & - & 141 & & - & 141 & - & - \\
\hline
\end{tabular}

\section{Discussion}

\section{Milk yield}

The average milk yield reported by [4-6] 2772.76 to $3710 \mathrm{~kg}$, the findings of above mention author are in agreement with finding of current study. [7], [8] reported that season of calving and parity had significant effect on the production of milk. In current study higher milk was observed in parity number $7^{\text {th }}$ may be due to low availability of data. It has been reported by $[7,9]$ that higher milk yield was observed in $2^{\text {nd }}$ and $3 r$ parity. Author has described that adaptability and performance of temperate were not observed better in subtropical areas. In our study higher milk production was observed in spring season and fall that indicates that better environmental temperature was suitable for Holstein Frisian in spring and fall season. Lower production of milk yield in summer may be due to heat stress and low availability of green fodder. Due to lower production during the summer season efforts are required to reduce environmental stress and amount of fresh air flow should be increased for higher production of animals. Whereas effect of calving year and sire was non-significant showing that there was no improvement made by sire and year. Hence due to this purpose imported semen from temperate areas can be used to increase the effectiveness of sire effect [10], Author has reported that increased in environmental temperature caused stressful condition for dairy animals, hence supply of fresh air is necessary for getting stress free environment. The results of heritability estimates observed low to moderate in our study, the findings of [11-13], who have also reported moderate results of heritability estimation ranges from 0.06 to $0.47,0.21$, to 0.04 , similar results were found repeatability estimation by $[6$, $14,15]$, who had reported low repeatability estimation for milk yield. That is may be due to unfavorable environmental conditions or low mount of data available. The different among above mention studies may be due to variation in environmental as well as management conditions of farm. According to $[4,6]$ who had also reported higher milk yield during spring season, they have reported that due to favorable environment and availability of fresh green fodder animals produces more amount of milk as compared to other seasons that is why the results for 
heritability and repeatability estimations were moderate to high in both researches.

\section{Lactation length}

Different author had been reported average lactation length range from 291.86 to 362 by $[4,7,11]$, the findings of lactation length in our study were also in agreement with above mention studies. The results of [10], are controversial than findings of current study, who had reported had significant effect on lactation length, while higher lactation length was observed relatively in those cows, which had calved in winter and fall. The mention difference among the studies may be due animal's sensitiveness to seasonal variation and also better feeding practices can also be the reason of early conception cause subsequent calving. It has been reported that repeat breeding, improper timely insemination and absence of heat are major reason for higher lactation length in cows. The findings for heritability and repeatability of $[10,16]$, are in also agreement, they had also reported moderate results for heritability and repeatability estimations $0.181 \pm 0.162$ and 0.060 .22 to 0.6 for lactation length, similar statement described by $[14,17]$ due to low estimation of heritability and low results for repeatability indicates that higher amount of environmental influence were found on the lactation length.

\section{Dry period}

The findings of $[5,19]$ reported dry period ranges between 129.63 to 281.33 While the results of dry period in current study was observed lower as compared to above mentioned researches. [19], reported that effect of season and sire were observed nonsignificant on dry period. It has also been reported by many researchers that low dry period in cows was observed due their drying up time happened in summer and fall with low availability of green fodder and high environmental temperatures. For the improvement of dry period authors had been suggested that better management can results in the betterment of reproductive traits and will definitely cause low dry period, low calving interval and brings profitability in farm. The results of heritability and repeatability in current study was found moderate for dry period, while findings of $[19,20]$ reported higher values for heritability and repeatability estimation such as $0.101 \pm 0.21$ and $0.08 \pm 0.08$ for dry period in Jersey and Holstein Frisian cattle. While findings of $[5,21]$ they had also reported moderate values

\section{Conclusions}

In current study due to low and moderate values for heritability and repeatability, it is concluded that these traits are highly influenced by environmental effects, so it is better to reduce environmental stress (heat stress) and fresh air flow should be provided during the summer season for better production.

\section{Author's contributions}

Conceived and designed the experiments: HA Kaleri \& SK Baloch. Performed the experiments: MA Baloch, A Kaleri, SA Umarni, GM Mari \& A Mari. Analyzed the data: RR Kaleri, MA Gopang \& IH Kakar. Contributed reagents/ analysis/ tools: RR Kaleri. Wrote the paper: HA Kaleri \& RR Kaleri.

\section{References}

1. Usman T, Gao G, Sohial SM, Ahmed S, Qioxing Li, Qureshi MS \& Yang Y. (2012). Performance traits study of Holstein Frisian cattle under subtropical environment. Journal of Plant and Animal Sciences 22: 92-95.

2. Mandokhial K, Kaleri HA, Kaleri RR, Kaleri, A \& Safi AS (2017). Study on the persistency of lactation in Holstein Friesian cattle. Pure Appl Biol 6(1): 159163.

3. Assadullah, Kaleri HA, Kaleri RR, Kaleri A, Kaleri AH \& Jalbani MA (2016). Correlation estimates between some 
performance traits of Holstein Frisian cattle. Sci Int (Lahore) 28(6): 5227-5228.

4. Sattar AR, Mirza HA Niazi KA \& Latif M (2005). Productive and reproductive performance of Holstein Frisian cows in Pakistan. Pak Vet J 25(2): 75-81.

5. Tadesse M, Thiengtham A, Pinyopummin and Prasanpanih S. (2010). Productive and reproductive performance of Holstein Frisian cows in Ethopia. Livestock Research Development for Rural 22(2).

6. Abdullah (2005). Factor affecting productive and reproductive traits and genetic and phenotypic correlation of various parameters of black and white Danish cattle dairy farm Quetta. Thesis submitted to Pakhtunkhwah Agriculture University Peshawar. P-29-80.

7. Tadesse M \& Dessie T (2003). Milk performance of zebu Holstein Frisian and their cross in Ethiopia, Livestock Research for Rural Development 3(15): 765-72.

8. Javed K, Afzal M, Sattar A \& Mirza RH. (2004). Environmental factors affecting milk yield in Frisian cows in Punjab, Pakistan. Pak Vet J 24(2): 4-7.

9. Javed K, Afzal M \& Ahmed I (2002). Environmental effects on lactation milk yield of Jersey cows in Pakistan. J Anim Plant Sci 12(3): 66-69.

10. Lakshmi BS, Gupta BR, Sudhakar K Prakash MG and Sharma S. (2009). Genetic analysis of productive performance of 642 Holstein Frisian x Sahiwal cows.Tamilnadu. $J$ Vet and Anim Sci 5(4): 143-48.

11. Qureshi MS Khan JM, Khan IH, Chaudhry RA, Ashraf K \& Khan BD (2002). Improvement in economic traits of local cattle through crossbreeding with Holstein Frisian semen. Pak Vet J 21(3): 11-18.

12. Bakir GA, Kaygissiz \& Ulker H. (2004). Estimates of geneti parameters of milk yield in Brown Swiss and Holstein
Frisian cattle. Pak J of Biol Sci 7 (7): 1198-1201.

13. Cilek S \& Sahin. (2009). Estimation of some genetic parameters heritability and repeatability for milk yield in Anatolian population of Holstein cows. Archive Zootechnica 12(1): 57-64.

14. El-Barbry, AS Badran A, Gili AE \& Badaay MF. (1999). Estimation of genetic parameters for lactation traits in German Frisian cattle raised in Egypt. Alexendria J of Agric Res 44(3): 13-37.

15. Ferreira GB \& Fernandes (2000). Genetic parameters for productive traits in Holstein cows in Gois state, Brazil. Revista-Brasilerira-de ZootechniaDair. Sci 93(2):421-26.

16. Kotch SM, Yaday C \& Gupta S. (1990). Non-genetic factors affecting lifetime production traits in Jersey cattle. Indi Vet $J$ 67(6): 520-523.

17. Becker, AW (1985). Manual of Quantitative genetics, $4^{\text {th }}$ Edition, Academic enterprise, Pullman, USA, P50.

18. Niazi AA \& Aleem M. (2003). Comparative studies on the reproductive efficiency of imported and local Born Frisian cows in Pakistan. Pak J of Biol Sci 3(4): 388-395.

19. Sohial SM, Ahmed A, Hafeez S Ahmed D, Jan Khan \& Rehman A (2010). Generic study of some reproductive traits of Jersey cattle under subtropical conditions. Sarhad J Agric 26(1):87-91.

20. Doekar DK \& Ulmek BR (1997). Genetic study of milk yield in Jersey cattle. J of Maharshtar Agric Uni 22(1): 219-220.

21. Khan UN, Benyshek LL \& Ahmed MD. (1988). Repeatability and heritability estimates for economic traits of native and crossbred dairy cattle. Pak J of Agric 24(2):317-21. 